\title{
Trends in the Magnitude and Frequency of Extreme Rainfall Regimes in Florida
}

\author{
Tasnuva Mahjabin ${ }^{1,3}$ and Omar I. Abdul-Aziz 2,3,*(1) \\ 1 Department of Civil and Environmental Engineering, The Pennsylvania State University, University Park, \\ PA 16802-1408, USA; tvm5451@psu.edu \\ 2 Department of Civil and Environmental Engineering, West Virginia University, Morgantown, \\ WV 26506-6103, USA \\ 3 Formerly at the Department of Civil and Environmental Engineering, Florida International University, \\ Miami, FL 33174, USA \\ * Correspondence: oiabdulaziz@mail.wvu.edu or omariaaziz@gmail.com; Tel.: +1-304-293-9929
}

Received: 2 August 2020; Accepted: 10 September 2020; Published: 16 September 2020

check for updates

\begin{abstract}
Trends in the extreme rainfall regimes were analyzed at 24 stations of Florida for four analysis periods: 1950-2010, 1960-2010, 1970-2010, and 1980-2010. A trend-free pre-whitening approach was utilized to correct data for autocorrelations. Non-parametric Mann-Kendall test and Theil-Sen approach were employed to detect and estimate trends in the magnitude of annual maximum rainfalls and in the number of annual above-threshold events (i.e., frequency). A bootstrap resampling approach was used to account for cross-correlations across sites and evaluate the global significance of trends at the $10 \%$ level $(p$-value $\leq 0.10)$. Dominant locally significant ( $p$-value $\leq 0.10)$ increasing trends were found in the magnitudes of 1-12 h extreme rainfalls for the longest period, and in $6 \mathrm{~h}$ to 7 day rainfalls for the shortest period. The trends in 2-12 h rainfalls were also globally significant (i.e., exceeded the trends that could occur by chance). In contrast, globally significant decreasing trends were noted in the annual number of 1-3 h, 1-6 h, and 3-6 h extreme rainfalls during 1950-2010, 1960-2010, and 1980-2010, respectively. Trends in the number of 1-7 day extreme rainfalls were mixed, lacking global significance. Our findings would guide stormwater management in tropical/subtropical environments of Florida and around the world.
\end{abstract}

Keywords: trends; extreme rainfalls; Florida; tropical/subtropical environments; Mann-Kendall test; stormwater management

\section{Introduction}

Changes in precipitation depth, duration, and frequency affect the overall hydrological and environmental processes. The IPCC assessment reports (AR4 and AR5) indicated increases in extreme precipitation events since the mid-20th century [1,2]. The general circulation models (GCMs) projected higher increases in extreme precipitations than the mean precipitations in many parts of the world [3-5]. Increase in heavy precipitations raises the risk of flash floods, more notably in urban settings [6,7]. However, the coarse-scale projections from GCMs can often miss the unique meteorological and climatic processes in Florida peninsula, which encounters large spatiotemporal variation in rainfalls [8,9]. Florida is home for critical crop agriculture, several national parks (e.g., Everglades), mass tourisms, and the fastest growing urban centers (e.g., Miami, Tampa, Orlando) of USA. Frequent tropical (e.g., hurricane) and non-tropical rainfall events, low elevations and flat topography, and sea level rise make Florida particularly vulnerable to flooding. Investigation of the long-term trends in extreme rainfall events is, therefore, crucial for agricultural, environmental, and economic sustainability of Florida and the U.S. 
Many studies have been conducted to detect long-term trends of precipitation in the U.S. and around the world. Among the earlier studies, Lettenmaier et al. [10] examined monthly precipitation trends for the continental U.S. during 1948-1988, and identified increases in precipitation from September through December especially for the central part of the country. Large increases in fall precipitations over several decades was also observed in the eastern U.S. [11] and in the central and southern U.S. [12]. Karl and Knight [13] estimated 10\% increase in annual precipitation over the U.S. for the duration of 1910-1996. More increasing than decreasing trends in annual precipitation were found in the U.S. central plains and Midwest over the past century [14]. Among the later studies, Sayemuzzaman and Jha [15] reported notable increasing trends in winter precipitations and decreasing trends in fall precipitation for the state of North Carolina (NC) during 1950-2009. They also found mixed (increasing/decreasing) trends in spring, summer, and annual precipitations for NC. Longueville et al. [16] found a significant decreasing trend in the annual total rainfall for Burkina Faso, West Africa during 1950-2013. Luong et al. [17] also reported a decreasing trend in the annual mean rainfall in Jeddah, Saudi Arabia during 1979-2018.

Previous studies have found it pivotal to identify and estimate trends in precipitation extremes so that the research outcomes can be used to implement a range of adaptation options to manage the potential stormwater quantity and quality. For example, Frich et al. [18] used a global dataset to investigate the impacts of climate change on the extreme events over the second half of the 20th century. They observed significant global increases in the extreme precipitation amounts and frequencies. Costa and Soares [19] found an evidence of increasing short-term precipitation intensity in the southern Portugal during the last three decades of 20th century. Burn et al. [20] reported generally increasing trends in the extreme rainfall events, particularly in summer season and in rainfall regimes of short durations, across British Columbia, Canada. In a follow up study, Burn and Taleghani [21] found more increasing than decreasing trends and larger changes in the longer duration rainfalls over entire Canada. Yilmaz et al. [22] examined trends in extreme rainfall data for Melbourne (Australia) and detected statistically significant increasing trends for storm durations of $30 \mathrm{~min}, 3 \mathrm{~h}$, and $48 \mathrm{~h}$. Longueville et al. [16] reported mixed increasing and decreasing trends in 1 and 5 day extreme rainfall magnitudes over Burkina Faso during 1950-2013. Malik et al. [23] detected increasing trends in 1 day extreme rainfalls during 1871-2012 in parts of Pakistan, northwest Himalaya, and central India. Luong et al. [17] found that extreme rainfalls had been more intense, but less frequent over Jeddah, Saudi Arabia during 1979-2018. On a global scale, however, Papalexiou and Montanari [24] reported overall increasing trends in extreme precipitations under global warming during 1960-2013.

Kunkel et al. [25] examined extreme precipitation events (1, 5, 10, and 30 day durations; with return periods of 1, 5, and 20 years) in the U.S. for 1895-2000. They found relatively high occurrences of extreme events during the late 20th/early 21st centuries. In a follow-up study, Kunkel et al. [26] used U.S. Cooperative Observer Network (COOP) data to assess the uncertainty in heavy precipitation frequency, and corroborated the findings of Kunkel et al. [25]. Mishra and Singh [27] fitted generalized extreme value (GEV) distribution to precipitation extremes in Texas. They identified distinguished patterns in 1, 7, and 30 day annual maximum events between pre- and post-climatic change periods (1925-1964 and 1965-2005, respectively). Keuser [28] investigated changes in mean and extreme precipitations in the metropolitan areas of Wisconsin for 1950-2006. They found no trends in extreme precipitations, but significant increasing trends for annual precipitation, particularly in the northern metropolises. Peterson et al. [29] concluded that the heavy precipitations had been increasing over the last half of 20th century in North America, and the average amount of wet days had also been increasing. Powell and Keim [30] found overall increasing trends in both magnitude and frequency of extreme rainfalls during 1948-2012 in the southeastern U.S. Armal et al. [31] reported mostly significant increasing trends in the annual frequency of above-threshold events for daily rainfalls during 1900-2014 over the contiguous U.S.

Several studies investigated the long-term precipitation trends and variability in Florida. Nadarajah [32] fitted GEV distribution to the annual maxima of daily rainfall data during 1901-2003 
for west-central Florida. The study found significant decreasing trends for majority stations. However, the study focused on a small region and did not represent the entire state of Florida. Martinez et al. [33] examined the monthly, seasonal, and annual precipitation trends over Florida, reporting significant decreasing trends in October and May rainfalls for the 1895-2009 and 1970-2009 periods, respectively. The study did not analyze trends in extreme rainfall regimes. Irizarry-Ortiz et al. [9] reported a general decline in wet season precipitations across Florida. They mainly focused on presenting historical trends in temperatures. Although they analyzed trends in 1-7 day extreme rainfalls, trends in 1-12 $\mathrm{h}$ extreme rainfalls remained unexplored. However, intense short duration rainfalls can lead to flash flooding; evident trends in short duration rainfalls typically represent underlying climatic changes [34]. Teegavarapu et al. [35] explored the links (teleconnections) of Atlantic Multi-decadal Oscillation (AMO) to the extreme rainfalls of hourly and daily durations over Florida. They found linkages of spatial and temporal variability in extreme precipitations with the warm (1942-1969 and 1995-2010) and cool (1970-1995) phases of AMO. However, given the different study focus, they did not estimate the overall long-term historical trends in extreme rainfalls of hourly and daily durations over Florida.

This paper aims to analyze the long-term trends in the magnitudes and frequencies of extreme rainfall regimes of hourly through daily durations over Florida. Hourly rainfalls from 24 gauge stations across Florida were processed and aggregated to derive the annual maximum time-series of rainfall magnitudes and the number of above-threshold (99th percentile) events for 12 durations: 1, 2, 3, 6, and $12 \mathrm{~h}$, as well as $1,2,3,4,5,6$, and 7 days. The analyses were conducted for four historical periods: 1950-2010, 1960-2010, 1970-2010, and 1980-2010. A trend-free pre-whitening approach was utilized to correct the derived annual time-series data for autocorrelations. Non-parametric Mann-Kendall test [36-38] and Theil-Sen approach [39,40] were employed to detect and estimate trends. A bootstrap resampling approach was used to account for cross-correlations across sites and evaluate the global (i.e., field) significance of trends, which indicated whether the number of rainfall stations with locally (i.e., at-site level) significant trends had exceeded the number expected to occur by chance.

\section{Materials and Methods}

\subsection{Study Area}

The study area represents the entire state of Florida (Figure 1). To interpret the spatial patterns of trends, we leveraged the boundaries of five water management districts: Northwest Florida, Suwannee River Basin, St. Johns River Basin, Southwest Florida, and South Florida. The major cities and towns of Florida are also stated on a separate map (Figure 2) to provide local context into the trend results.

The state of Florida has a total area of 58,560 square miles with a population of around 19 million. The geographic area can be divided into two major parts: Florida Panhandle and Peninsula. The peninsula is located between the Atlantic Ocean, the Gulf of Mexico, and the Straits of Florida. The climate for majority of the state can be characterized as subtropical; however, the southernmost areas experience a tropical climate. High temperature and high relative humidity classify this state as hot and humid for most of the year [9]. Florida has mainly two distinct seasons (wet and dry). The wet season typically persists from May to October; the dry season lasts from November to April [35]. The average annual rainfall is about $1360 \mathrm{~mm} /$ year [41]. More than half of the rain occurs in the wet season, which is associated with thunderstorms, squalls, and tropical cyclones [42]. The panhandle experiences maximum rainfall in the region, whereas the least rainfall occurs in the keys [43]. The sea breeze circulation of the coastal areas has an effect on enhancing convection that characterizes the wet season precipitation, whereas the dry season precipitation is largely influenced by the frontal systems [44]. In south Florida, a higher amount of precipitation occurs in the urbanized east coast than the interior and west coast [9]. The AMO, El Niño Southern Oscillation (ENSO), and Pacific Decadal Oscillation (PDO) influence rainfalls mainly in central and south Florida [45]. 


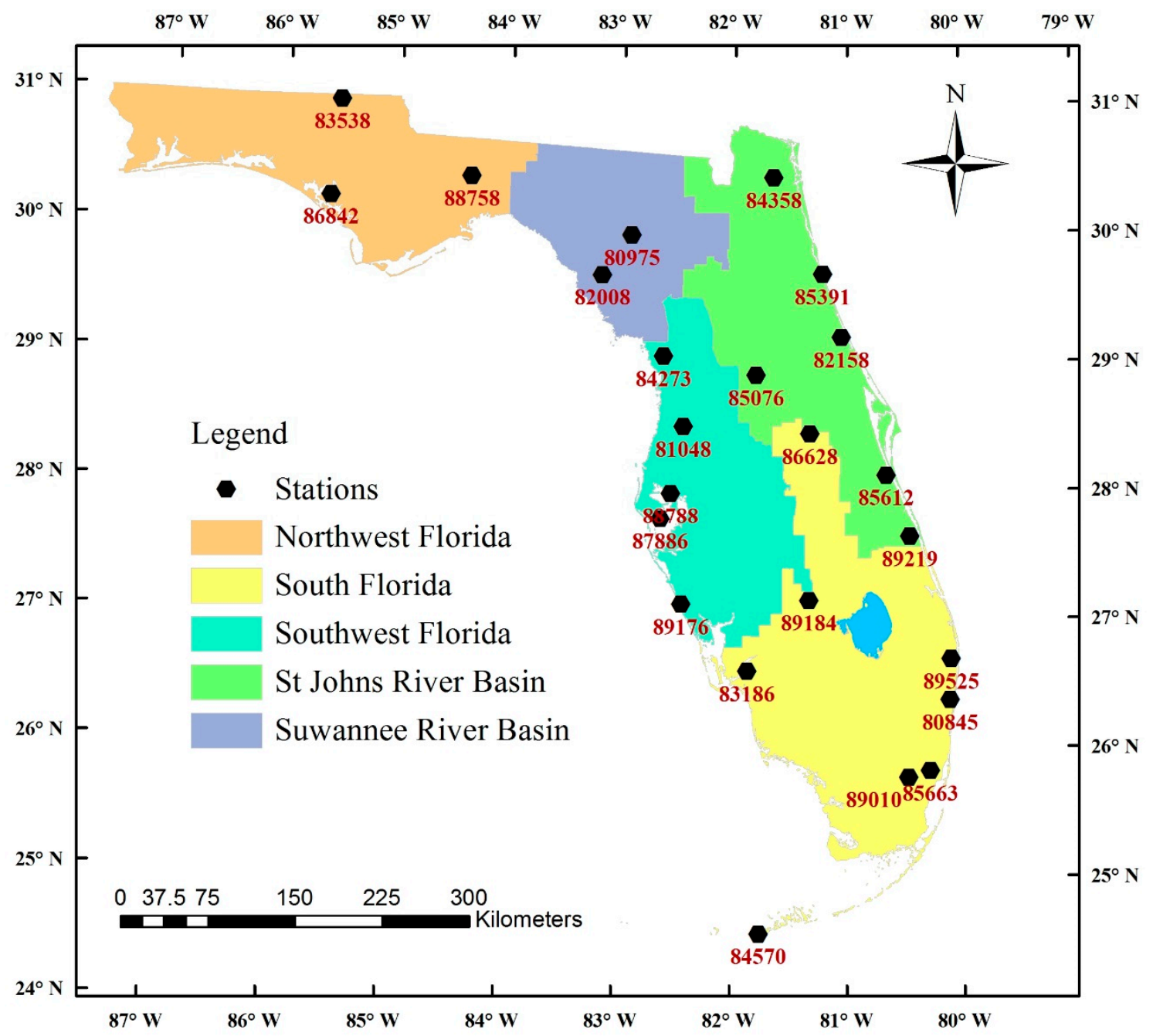

Figure 1. Study area map indicating the stations used for long-term precipitation trend analysis. Number below the station indicates the COOP ID provided by the U.S. National Climatic Data Center.

\subsection{Data Sets}

The hourly precipitation data of 1950-2010 were collected from the National Climatic Data Center [46] for 24 rain gauge stations across Florida (Figure 1, Table 1). The rain gauge stations were selected based on their record length and completeness. Any year having more than $30 \%$ missing values was eliminated from the dataset. The hourly data were aggregated to derive the rainfall events for durations of 2, 3,6, and $12 \mathrm{~h}$, as well as of 1, 2, 3, 4, 5, 6, and 7 days. The dataset was then used to derive, on an annual basis, the magnitude of the maximum rainfall events and the number of above-threshold events (i.e., frequency) for the 12 individual durations. The thresholds were defined by sorting data for each rainfall station and duration in an ascending order. The 99th percentile rainfall magnitudes were used as the threshold values for various durations at each station separately for the entire data period (1950-2010). Trends in the magnitude and number of above-threshold events for different extremes were investigated for four analysis periods: 1950-2010, 1960-2010, 1970-2010, and 1980-2010. Stations having more than four missing years in each period were excluded from the analyses to avoid any bias from excessive missing data. The longer periods of 1950-2010 and 1960-2010 included 13 and 18 stations, respectively; each of the later periods (1970-2010, 1980-2010) had 24 stations. 


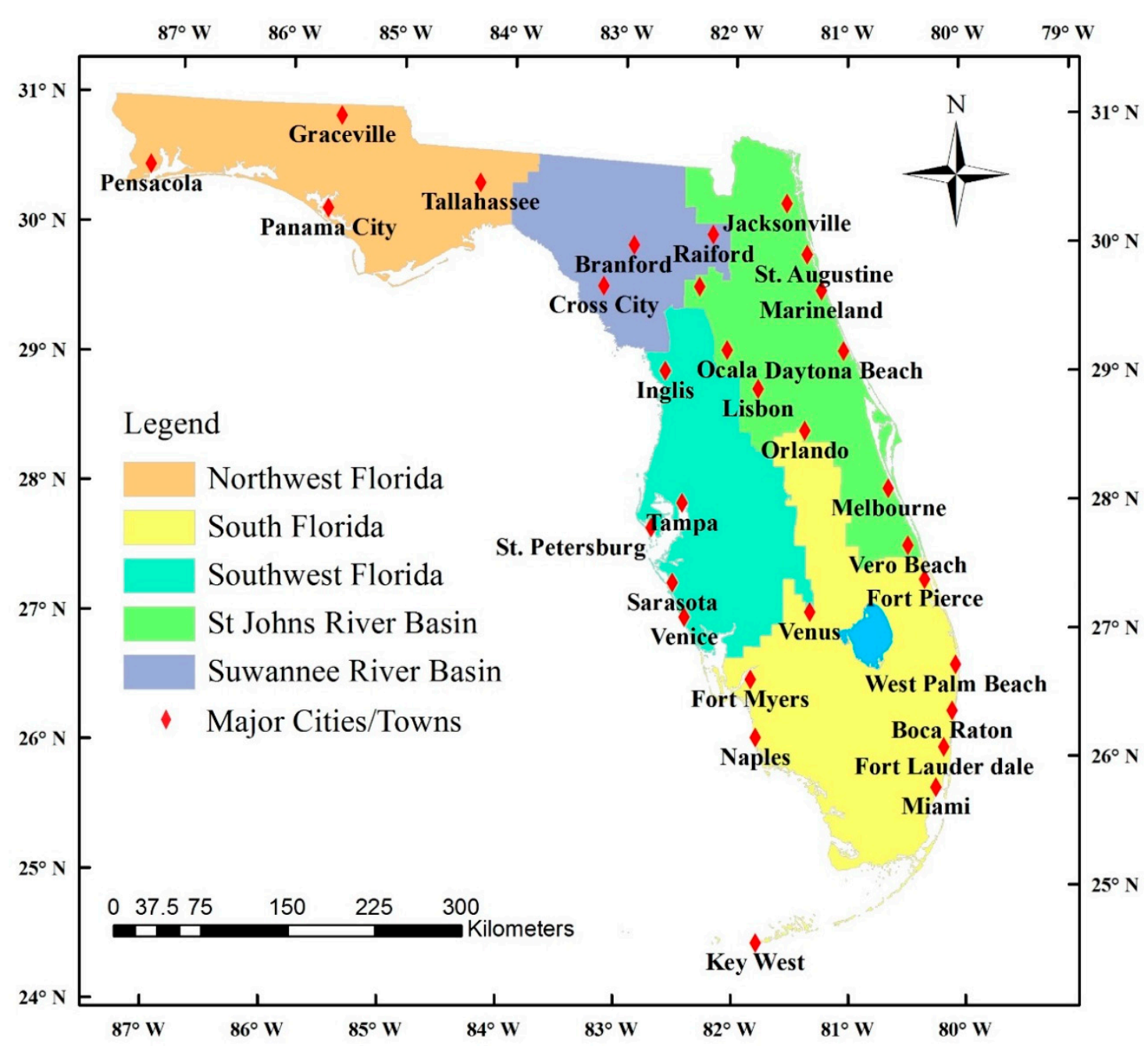

Figure 2. The major cities and towns of mainland Florida. The legend describes the five major water management districts of Florida.

\subsection{Methods}

The Mann-Kendall non-parametric method [36-38] was used to detect trends in the extreme rainfall time-series of different durations. Many studies have effectively used this rank-based method to determine trends in hydro-climatological data [47-49]. Mann-Kendall test is well-documented in literature (see Burn and Hag Elnur [50]; Burn et al. [51]; Novotny and Stefan [52]). A comprehensive and complete description of the methodology employed for this current paper is available in Burn et al. [51]. Before applying this test, each time-series was corrected for auto or serial correlations by using a trend-free pre-whitening approach $[51,53,54]$. The Mann-Kendall test provided the local or at-site level significance of the detected trends. The global or field significance of the detected trends were determined by employing a bootstrap resampling approach [50,51]. The global significance test accounted for the cross-correlation structure of data across all stations and indicated whether the number of rainfall stations with locally significant trends in extreme rainfall of each duration had exceeded the number expected to occur by chance. The detected trends were evaluated at the $10 \%$ significance level $(p$-value $\leq 0.10)$ for both Mann-Kendall test statistic and bootstrap methods. The trend slopes $(\beta)$ were estimated by using the Theil-Sen approach $[39,40]$. Sen's estimator has been extensively used as a robust predictor of trend slope in many previous studies [51,55-57]. 
Table 1. Summary of the 24 rainfall gauging stations located across Florida.

\begin{tabular}{|c|c|c|c|c|c|c|}
\hline \multirow{2}{*}{$\begin{array}{l}\text { COOP } \\
\text { Site ID }\end{array}$} & \multirow{2}{*}{ Station Name } & \multirow{2}{*}{$\begin{array}{l}\text { Latitude } \\
\left({ }^{\circ} \mathbf{N}\right)\end{array}$} & \multirow{2}{*}{$\begin{array}{l}\text { Longitude } \\
\left({ }^{\circ} \mathrm{W}\right)\end{array}$} & \multirow{2}{*}{$\begin{array}{c}\text { Elevation } \\
\text { (m) }\end{array}$} & \multicolumn{2}{|c|}{ Period of Record } \\
\hline & & & & & Start & End \\
\hline 084570 & Key West International Airport & 24.55 & -81.75 & 1.2 & 3/1/1958 & $12 / 31 / 2010$ \\
\hline 089010 & Trail Glade Ranges & 25.77 & -80.47 & 3.0 & $1 / 1 / 1973$ & $12 / 1 / 2010$ \\
\hline 085663 & Miami International Airport & 25.82 & -80.28 & 7.0 & 1/1/1951 & $12 / 31 / 2010$ \\
\hline 080845 & Boca Raton & 26.37 & -80.11 & 4.3 & $1 / 1 / 1950$ & $12 / 1 / 2010$ \\
\hline 083186 & Fort Myers Page Field Airport & 26.59 & -81.86 & 4.6 & $1 / 1 / 1960$ & $12 / 27 / 2010$ \\
\hline 089525 & West Palm Beach International Airport & 26.68 & -80.10 & 5.8 & $1 / 1 / 1950$ & $12 / 26 / 2010$ \\
\hline 089176 & Venice & 27.10 & -82.44 & 2.4 & 2/1/1950 & $12 / 26 / 2010$ \\
\hline 089184 & Venus & 27.14 & -81.33 & 49.1 & $1 / 1 / 1950$ & $12 / 26 / 2010$ \\
\hline 089219 & Vero Beach 4 SE & 27.63 & -80.45 & 6.1 & $5 / 1 / 1965$ & $12 / 21 / 2010$ \\
\hline 087886 & St. Petersburg Albert Whitted Airport & 27.76 & -82.63 & 2.4 & $1 / 1 / 1950$ & $11 / 1 / 2010$ \\
\hline 088788 & Tampa International Airport & 27.96 & -82.54 & 5.8 & $1 / 1 / 1950$ & $12 / 26 / 2010$ \\
\hline 085612 & Melbourne Weather Forecast Office & 28.11 & -80.65 & 10.7 & $1 / 1 / 1950$ & $12 / 22 / 2010$ \\
\hline 086628 & Orlando International Airport & 28.43 & -81.33 & 27.4 & $5 / 1 / 1974$ & $12 / 26 / 2010$ \\
\hline 081048 & Brooksville 7 SSW & 28.48 & -82.44 & 20.4 & 1/1/1972 & $12 / 18 / 2010$ \\
\hline 085076 & Lisbon & 28.88 & -81.80 & 21.0 & $1 / 1 / 1959$ & $12 / 25 / 2010$ \\
\hline 084273 & Inglis $3 \mathrm{E}$ & 29.03 & -82.62 & 9.1 & $1 / 1 / 1950$ & $12 / 26 / 2010$ \\
\hline 082158 & Daytona Beach International Airport & 29.18 & -81.05 & 9.4 & $1 / 1 / 1950$ & $12 / 26 / 2010$ \\
\hline 082008 & Cross City 2 WNW & 29.65 & -83.17 & 12.8 & $7 / 1 / 1966$ & $12 / 25 / 2010$ \\
\hline 085391 & Marineland & 29.67 & -81.22 & 1.5 & $1 / 1 / 1950$ & $12 / 25 / 2010$ \\
\hline 080975 & Branford & 29.96 & -82.91 & 9.1 & $1 / 1 / 1950$ & $12 / 25 / 2010$ \\
\hline 086842 & Panama City & 30.22 & -85.60 & 9.8 & $1 / 1 / 1972$ & $12 / 25 / 2010$ \\
\hline 088758 & Tallahassee Regional Airport & 30.39 & -84.35 & 16.8 & 6/1/1958 & $12 / 26 / 2010$ \\
\hline 084358 & Jacksonville International Airport & 30.42 & -81.65 & 11.9 & $1 / 1 / 1950$ & $12 / 26 / 2010$ \\
\hline 083538 & Graceville 1SW & 30.96 & -85.53 & 48.8 & $1 / 1 / 1950$ & $12 / 25 / 2010$ \\
\hline
\end{tabular}

Note: The COOP station IDs were provided by the U.S. National Climatic Data Center.

\section{Results}

\subsection{Trends in the Magnitude of Annual Maximum Events}

Magnitude of the annual maximum rainfalls mostly exhibited more increasing than decreasing significant trends in Florida across the different periods of analysis (Table 2). During the longest study period of 1950-2010 (61 years), only significant increasing trends were found in the 1-12 h and 1 day extreme rainfalls, whereas 2-7 day extreme rainfalls had no significant trends. Slope of the locally significant trends typically increased with the increased durations, ranging from 0.15 to $0.64 \mathrm{~mm} / \mathrm{year}$ for $1 \mathrm{~h}$ to 1 day rainfalls, respectively (Table 2). The number of stations with the significant trends ranged from $8 \%$ (1 station) to 38\% (5 stations), out of the 13 stations with available data records for this 61 year period. Based on the bootstrap resampling method, the increasing trends in only the 2-12 $\mathrm{h}$ extreme rainfall regimes were globally significant.

The 1960-2010 (51 years) period also had locally significant increasing only trends in extreme rainfalls of 1-12 h durations (except for the $3 \mathrm{~h}$ rainfall), demonstrating an increase of 0.23 to $0.76 \mathrm{~mm} /$ year (Table 2). Additionally, the 51 year time-frame indicated significant increasing trends in the 4-7 day rainfalls ( 0.72 to $0.85 \mathrm{~mm} /$ year), although the $1-3$ day extreme rainfalls had no significant trends. However, the detected locally significant trends were found at only $6 \%$ ( 1 station) of 18 available stations and were not globally significant.

The 1970-2010 (41 years) period did not exhibit any significant trends in the 1-3 h extreme rainfalls (Table 2). The 41 year period had significant increasing trends in the $6 \mathrm{~h}$ to 7 day rainfalls ( 0.73 to $1.49 \mathrm{~mm} /$ year). Additionally, the 5 day rainfall also exhibited significant decreasing trends (1.04 mm/year). The locally significant increasing trends for the various durations were found at $4 \%$ ( 1 station) to $25 \%$ (6 stations) of the 24 available stations. The significant decreasing trend in the 5 day rainfall was noted for a single station (4\%). Only the trends in 6 and 7 day extreme rainfalls were globally significant for this study period. 
Table 2. Percentage (\%) of stations with significant trends and the corresponding trend-slopes (in parentheses; $\mathrm{mm} /$ year) for the magnitude of annual maximum rainfalls.

\begin{tabular}{|c|c|c|c|c|c|c|c|c|}
\hline \multirow{3}{*}{$\begin{array}{c}\text { Rainfall } \\
\text { Durations }\end{array}$} & \multicolumn{8}{|c|}{ Periods of Analysis } \\
\hline & \multicolumn{2}{|c|}{$\begin{array}{c}\text { 1950-2010 } \\
\text { (13 Stations) }\end{array}$} & \multicolumn{2}{|c|}{$\begin{array}{c}1960-2010 \\
\text { (18 Stations) }\end{array}$} & \multicolumn{2}{|c|}{$\begin{array}{c}1970-2010 \\
\text { (24 Stations) }\end{array}$} & \multicolumn{2}{|c|}{$\begin{array}{c}1980-2010 \\
\text { (24 Stations) }\end{array}$} \\
\hline & +ve & - ve & +ve & - ve & +ve & - ve & + ve & - ve \\
\hline $1 \mathrm{~h}$ & $15(0.15)$ & 0 & $6(0.24)$ & 0 & 0 & 0 & $8(0.49)$ & $8(0.60)$ \\
\hline $2 \mathrm{~h}$ & $38(0.26)$ & 0 & $6(0.23)$ & 0 & 0 & 0 & $4(0.76)$ & $8(0.83)$ \\
\hline $3 \mathrm{~h}$ & $31(0.36)$ & 0 & 0 & 0 & 0 & 0 & $4(0.97)$ & $8(0.93)$ \\
\hline $6 \mathrm{~h}$ & $23(0.48)$ & 0 & $6(0.76)$ & 0 & $4(0.89)$ & 0 & $8(1.41)$ & $4(0.95)$ \\
\hline $12 \mathrm{~h}$ & $23(0.53)$ & 0 & $6(0.70)$ & 0 & $8(0.73)$ & 0 & $13(1.50)$ & $4(0.89)$ \\
\hline 1 day & $8(0.64)$ & 0 & 0 & 0 & $8(1.15)$ & 0 & $13(2.03)$ & 0 \\
\hline 2 days & 0 & 0 & 0 & 0 & $17(1.13)$ & 0 & $13(2.07)$ & $4(1.74)$ \\
\hline 3 days & 0 & 0 & 0 & 0 & $17(1.30)$ & 0 & $13(2.46)$ & $4(2.18)$ \\
\hline 4 days & 0 & 0 & $6(0.72)$ & 0 & 13 (1.42) & 0 & $13(2.58)$ & $8(2.29)$ \\
\hline 5 days & 0 & 0 & $6(0.83)$ & 0 & $8(1.45)$ & $4(1.04)$ & $13(2.54)$ & $8(2.15)$ \\
\hline 6 days & 0 & 0 & $6(0.79)$ & 0 & $21(1.30)$ & 0 & $17(2.22)$ & $8(2.08)$ \\
\hline 7 days & 0 & 0 & $6(0.85)$ & 0 & 25 (1.49) & 0 & $13(2.76)$ & $8(2.16)$ \\
\hline
\end{tabular}

Notes: Entries in bold indicate globally significant trends at the $10 \%$ level $(p$-value $\leq 0.10)$. Increasing and decreasing trends are indicated by positive (+ve) and negative (-ve) signs, respectively. For each duration, reported slopes represent the average of Sen slopes across the stations with significant trends ( $p$-value $\leq 0.10)$.

The 1980-2010 (31 year) period showed both locally significant increasing and decreasing trends in extreme rainfalls of various durations (Table 2). The shorter rainfall regimes (1-3 h) had either equal number of sites with both type of trends or more stations with decreasing trends. However, the medium to longer duration rainfalls ( $6 \mathrm{~h}$ to 7 day) exhibited consistently higher percentages of increasing than decreasing trends. In particular, the 1 day extreme rainfall regime did not have any station with a significant decreasing trend. The trend slopes suggested an increase of 0.49 to $2.76 \mathrm{~mm} / \mathrm{year}$, as well as a decrease of 0.60 to $2.29 \mathrm{~mm} /$ year. However, number of stations demonstrating a significant trend (increasing or decreasing) ranged from $4 \%$ (1 station) to $17 \%$ (4 stations), out of the 24 available stations. Based on the bootstrap resampling method, none of the detected trends in the extreme rainfall regimes were globally significant for this period.

\subsection{Trends in the Annual Number of Above-Threshold Events}

The annual number of above-threshold events indicated dominant decreasing trends in the shorter duration rainfalls for all periods of analysis (Table 3). During 1950-2010, 15\% (2 stations) to $54 \%$ ( 7 stations) of 13 available stations had locally significant decreasing trends for $1-6 \mathrm{~h}$ rainfalls, representing a rate of decrease by 0.45 to 0.70 events/year. Based on the product (multiplication) of the fractional trend-slopes and period of analysis, the number of above-threshold events had decreased by approximately 27 to 43 events for 1-6 h rainfalls during the 61 year period. In contrast, significant increasing trends were found only for $1 \mathrm{~h}$ ( 0.30 events/year) and 2 day ( 0.68 events/year) rainfalls for 1 and 2 stations, respectively. Over this longest study period, the number of $1 \mathrm{~h}$ and 2 day rainfalls, therefore, increased by 18 and 41 events, respectively. However, the increasing trends in $1 \mathrm{~h}$ rainfall were displayed by a much lower number $(8 \%)$ of stations than that $(54 \%)$ exhibiting a decreasing trend. In fact, only the decreasing trends in 1-3 h rainfalls were globally significant. Furthermore, trends in the annual number of other extreme rainfall regimes (12 h, 1 day, and 2-7 day) were not statistically significant. 
Table 3. Percentage (\%) of stations with significant trends and the corresponding trend-slopes (in parentheses; events/year) for the annual number of above-threshold events.

\begin{tabular}{|c|c|c|c|c|c|c|c|c|}
\hline \multirow{3}{*}{$\begin{array}{c}\text { Rainfall } \\
\text { Durations }\end{array}$} & \multicolumn{8}{|c|}{ Periods of Analysis } \\
\hline & \multicolumn{2}{|c|}{$\begin{array}{c}1950-2010 \\
(13 \text { Stations })\end{array}$} & \multicolumn{2}{|c|}{$\begin{array}{c}\text { 1960-2010 } \\
\text { (18 Stations) }\end{array}$} & \multicolumn{2}{|c|}{$\begin{array}{c}1970-2010 \\
\text { (24 Stations) }\end{array}$} & \multicolumn{2}{|c|}{$\begin{array}{c}1980-2010 \\
\text { (24 Stations) }\end{array}$} \\
\hline & +ve & - ve & +ve & -ve & +ve & $-\mathbf{v e}$ & +ve & -ve \\
\hline $1 \mathrm{~h}$ & $8(0.30)$ & $54(0.70)$ & $6(0.25)$ & $44(0.65)$ & $4(0.48)$ & $17(0.58)$ & $4(1.07)$ & $8(1.38)$ \\
\hline $2 \mathrm{~h}$ & 0 & $31(0.45)$ & $6(0.35)$ & $28(0.58)$ & $8(0.52)$ & $17(0.72)$ & $4(1.05)$ & $17(1.08)$ \\
\hline $3 \mathrm{~h}$ & 0 & $23(0.46)$ & $6(0.44)$ & $28(0.56)$ & $8(0.63)$ & 17 (0.73) & 0 & 21 (1.06) \\
\hline $6 \mathrm{~h}$ & 0 & $15(0.50)$ & 0 & $22(0.56)$ & $8(0.82)$ & $17(0.76)$ & 0 & $21(1.36)$ \\
\hline $12 \mathrm{~h}$ & 0 & 0 & 0 & 0 & $8(1.01)$ & $8(0.77)$ & 0 & $17(1.56)$ \\
\hline 1 day & 0 & 0 & 0 & 0 & $8(1.18)$ & 0 & $4(1.82)$ & $8(2.15)$ \\
\hline 2 days & $15(0.68)$ & 0 & 0 & 0 & 0 & 0 & 0 & $8(2.94)$ \\
\hline 3 days & 0 & 0 & 0 & 0 & $4(1.30)$ & 0 & $8(2.24)$ & $13(2.52)$ \\
\hline 4 days & 0 & 0 & 0 & 0 & $8(1.09)$ & 0 & $4(3.25)$ & $13(2.42)$ \\
\hline 5 days & 0 & 0 & 0 & 0 & $13(0.90)$ & 0 & $4(2.15)$ & $8(3.19)$ \\
\hline 6 days & 0 & 0 & 0 & 0 & $17(1.00)$ & 0 & $17(1.79)$ & $13(2.51)$ \\
\hline 7 days & 0 & 0 & $6(0.21)$ & $6(0.37)$ & $13(0.83)$ & 0 & $17(2.27)$ & $8(2.48)$ \\
\hline
\end{tabular}

Notes: Entries in bold indicate field (globally) significant trends at the $10 \%$ level ( $p$-value $\leq 0.10)$. Increasing and decreasing trends are indicated by positive (+ve) and negative ( $-v e)$ signs, respectively. For each duration, reported slopes represent the average of Sen slopes across the stations with significant trends ( $p$-value $\leq 0.10$ ).

The 1960-2010 period exhibited 22 to $44 \%$ (4 to 8 stations, respectively) of 18 available stations with locally and globally significant decreasing trends ( 0.56 to 0.65 events/year) in the annual number of $1-6 \mathrm{~h}$ rainfalls (Table 3 ). However, $6 \%$ station ( 1 station) also showed a significant increasing trend in the number of $1-3 \mathrm{~h}$ rainfalls at the rates of 0.25 to 0.44 events/year. Further, significant increasing ( 0.21 events/year) and decreasing ( 0.37 events/year) trends were found in the 7 day rainfall for an equal number $(6 \%)$ of stations. However, the increasing trends in 1-3 h rainfalls and the mixed trends in 7 day rainfall were not globally significant. Further, no trends in the annual number of $12 \mathrm{~h}$ to 6 day rainfalls were statistically significant. The product of the fractional trend-slopes and period of analysis suggested that the number of above-threshold events for 1-6 h rainfalls had decreased by 29 to 33 events during the 51 year period. In contrast, the number of above-threshold events for $1-3 \mathrm{~h}$ rainfalls for a much smaller percentage of stations increased by 13 to 22 events. For a similarly small percentage of stations, the number of 7 day rainfall increased and decreased by 11 and 19 events, respectively.

The 1970-2010 period had 17\% (4 stations) and 4 to $8 \%$ (1 to 2 stations) of 24 available stations with, respectively, locally significant decreasing and increasing trends in the annual number of 1-6 $\mathrm{h}$ rainfalls (Table 3). The decreasing trends ranged from 0.58 to 0.76 events/year, whereas the increasing trends ranged from 0.48 to 0.82 events/year. The number of $12 \mathrm{~h}$ rainfall had an equal number $(8 \%)$ of stations with locally significant increasing and decreasing trends at the rates of 0.77 to 1.01 events/year. The annual number of 2 day rainfall did not have any significant trends. However, locally significant increasing only trends were found in the number of 1 day and 3-7 day rainfalls at the rates of 0.83 to 1.30 events/year at 4 to $17 \%$ stations. Based on the product of fractional trend-slopes and the period of analysis, the number of above-threshold events for 1-6 h rainfalls had decreased and increased (albeit at fewer stations), respectively, by 24 to 31 and 20 to 34 events. In contrast, the number of $12 \mathrm{~h}$ rainfall increased and decreased by 41 and 32 events, respectively. Further, the number of 1 day and 3-7 day rainfalls increased by 34 to 53 events. However, no trends were globally significant in this 41 year period of analysis.

The 1980-2010 period demonstrated more decreasing than increasing trends in all but 6-7 day rainfalls (Table 3). The annual number of $1 \mathrm{~h}$ to 5 day rainfalls had significant decreasing trends at 8 to $21 \%$ ( 2 to 5 stations) of 24 available stations. At the estimated rates of 1.06 to 3.19 events/year, the number of $1 \mathrm{~h}$ to 5 day rainfalls decreased by 33 to 99 events over the 31 year period of analysis. Except for the 3-12 $\mathrm{h}$ and 2 day rainfalls, the 1-2 h, 1 day, and 3-5 day rainfalls also had significant 
increasing trends (1.05 to 3.25 events/year) at 4 to $8 \%$ (1 to 2$)$ stations, suggesting an increase by 33 to 101 events. However, only the decreasing trends in the 3-6 h rainfalls were globally significant. In contrast, the number of 6-7 day rainfalls exhibited more increasing than decreasing trends, although no trends were globally significant. Each of the two rainfall regimes had locally significant increasing trends (1.79 to 2.27 events/year) at $17 \%$ (i.e., 4 of 24 ) stations. In contrast, the number of $6-7$ day rainfall exhibited decreasing trends at 8 to $13 \%$ (2 to 3) stations at the rates of 2.48 to 2.51 events/year. Based on the estimated rates and the analysis period, the 6-7 day extreme rainfalls increased and decreased, respectively, by 55 to 70 and 77 to 78 events during 1980-2010.

\subsection{Spatial Patterns of Trends}

\subsubsection{Spatial Patterns of Trends for the Magnitude of Annual Maximum Events}

Spatial distribution of stations exhibiting increasing (upward) or decreasing (downward) trends for annual maximum rainfalls indicated emerging patterns across Florida (Figures 3 and 4). The spatial patterns were demonstrated by example rainfall regimes for the longest (1950-2010) and the shortest (1980-2010) periods along with slopes (mm/year) of the locally significant trends.

During 1950-2010, $1 \mathrm{~h}$ rainfall exhibited prevalent increasing trends (albeit mostly non-significant) across Florida (Figure 3a), except for 2 stations in the northeast region of St. Johns River Basin (Figure 1) presenting non-significant decreasing trends. However, increasing trends at only 2 stations located in the upper southwest Florida (Inglis) and Suwannee River Basin (Branford) were statistically significant (see Figure 2 for the locations of cities and towns). Spatial patterns of the 2 and $6 \mathrm{~h}$ rainfalls (Figure 3b,c) were largely similar to that of $1 \mathrm{~h}$ rainfall (Figure $3 \mathrm{~b}$ ). However, significant increasing trends in the $2 \mathrm{~h}$ rainfall were noted for a higher number of stations-located in northwest Florida (Graceville, Branford), southwest Florida (St. Petersburg), upper St. Johns River Basin (Melbourne), and south Florida (West Palm Beach). The stations in West Palm Beach, Melbourne, and Graceville also exhibited significant increasing trends in the $6 \mathrm{~h}$ rainfall (Figure 3c). Among the daily extreme rainfall regimes, the 1 day rainfall had a significant (increasing) trend at only the Melbourne station during 1950-2010 (Figure 3d).

During 1980-2010, mixed increasing and decreasing trends were observed for $1 \mathrm{~h}$ extreme rainfall (Figure 4a). Significant increasing trends were noted in the northwest Florida (Tallahassee) and lower St. Johns Basin (Jacksonville), while significant decreasing trends were apparent in west-central St. Johns Basin (Lisbon) and south Florida (Boca Raton). Stations in southwest Florida exhibited mostly increasing, but non-significant trends. Stations in the Suwannee Basin and lower south Florida (e.g., Key West) showed non-significant decreasing trends. Spatial patterns of trends in 2 h extreme rainfall (Figure $4 \mathrm{~b}$ ) were similar to that of $1 \mathrm{~h}$ rainfall, with some notable exceptions. For example, the $2 \mathrm{~h}$ rainfall had non-significant increasing and decreasing trends, respectively, at the Jacksonville and Boca Raton stations. Additionally, the Vero Beach station (upper St. Johns Basin) had a significant decreasing trend for the $2 \mathrm{~h}$ rainfall. However, the medium to longer duration rainfalls exhibited contrasting spatial distributions of the identified trends. For example, significant increasing trends were found for $12 \mathrm{~h}$ (Figure $4 \mathrm{c}$ ) and 5 day (Figure $4 \mathrm{~d}$ ) extreme rainfalls in south Florida (West Palm Beach) and upper St. John Basin (Melbourne). Additionally, significant increasing trends were noted in Jacksonville (lower St. Johns Basin) and Tampa (southwest Florida) for the $12 \mathrm{~h}$ and 5 day rainfalls, respectively. However, significant decreasing trends were evident for both rainfall regimes in Suwanee River Basin (Cross City). Further, the 5 day rainfall had a decreasing trend in Vero Beach of the upper St. Johns Basin. 

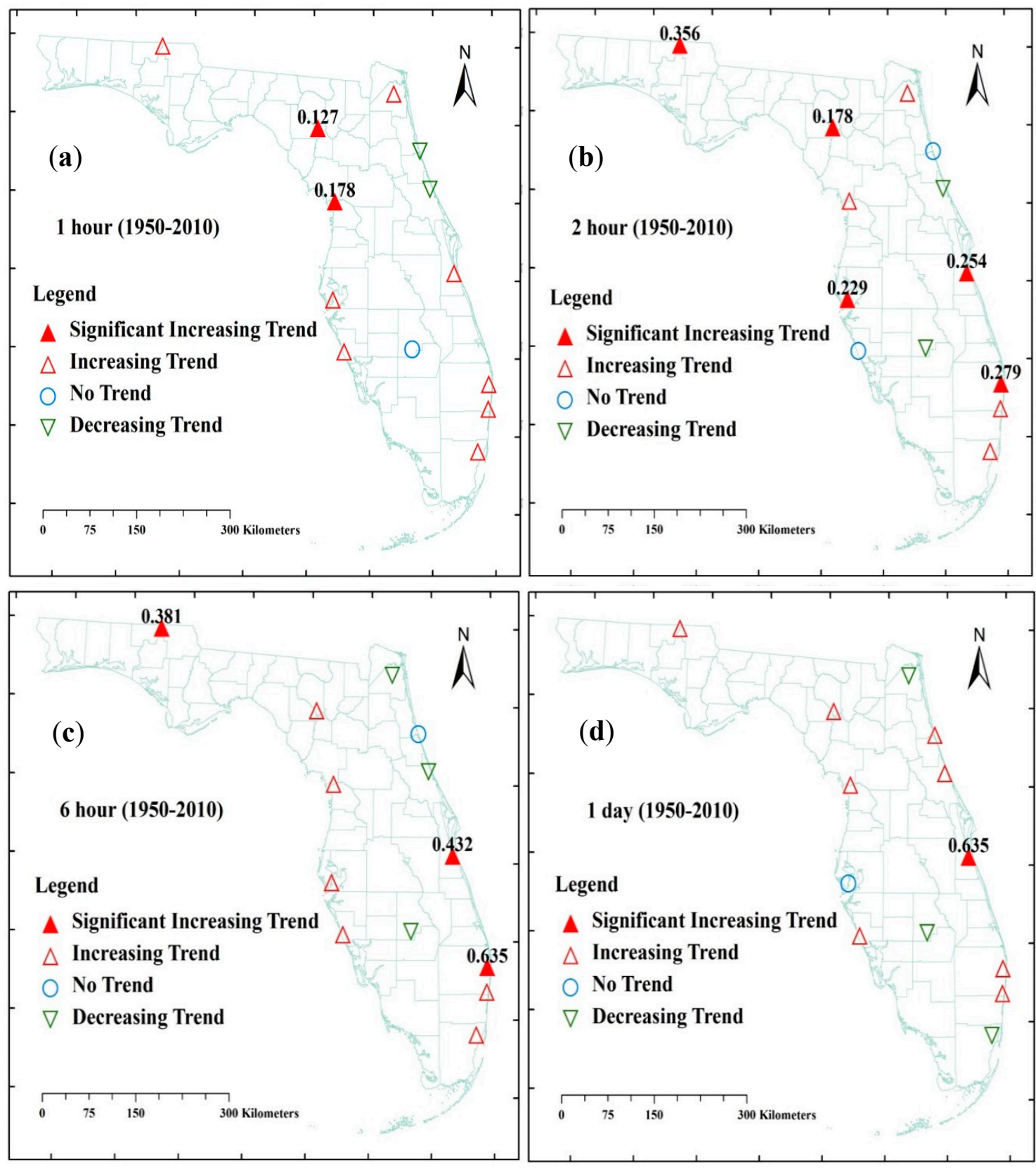

Figure 3. Spatial pattern of the trend results for the annual maximum rainfalls of (a) $1 \mathrm{~h},(\mathbf{b}) 2 \mathrm{~h}$, (c) $6 \mathrm{~h}$, and (d) 1 day durations for the 1950-2010 analysis period. The slope value (mm/year) for locally significant trend is also indicated.

\subsubsection{Spatial Patterns of Trends for the Number of Above-Threshold Events}

During the longest analysis period (1950-2010), significant and predominant decreasing trends were observed in the number of above-threshold events for $1 \mathrm{~h}$ rainfall (Figure 5a) for stations in northwest Florida (Graceville), southwest Florida (Inglis, St. Petersburg, Venice, Venus), and in St. Johns Basin (Melbourne, Marineland). However, the number of $1 \mathrm{~h}$ rainfall had a significant increasing trend in south Florida (Boca Raton). The annual number of $2 \mathrm{~h}$ extreme rainfall (Figure $5 \mathrm{~b}$ ) exhibited significant decreasing trends for the stations in Graceville, Branford, Inglis, and St. Petersburg, representing northwest Florida, Suwanee River Basin, and southwest Florida. The stations in Venus and St. Petersburg also had significant decreasing trends in the number of $6 \mathrm{~h}$ rainfall (Figure 5c). In contrast, stations located in Graceville (northwest Florida) and West Palm Beach (south Florida) 
exhibited significant increasing trends in the number of 2 day rainfall (Figure 5d). However, most parts of Florida had non-significant increasing/decreasing trends in the annual number of $6 \mathrm{~h}$ and 2 day extreme rainfall regimes during the 61 year period.

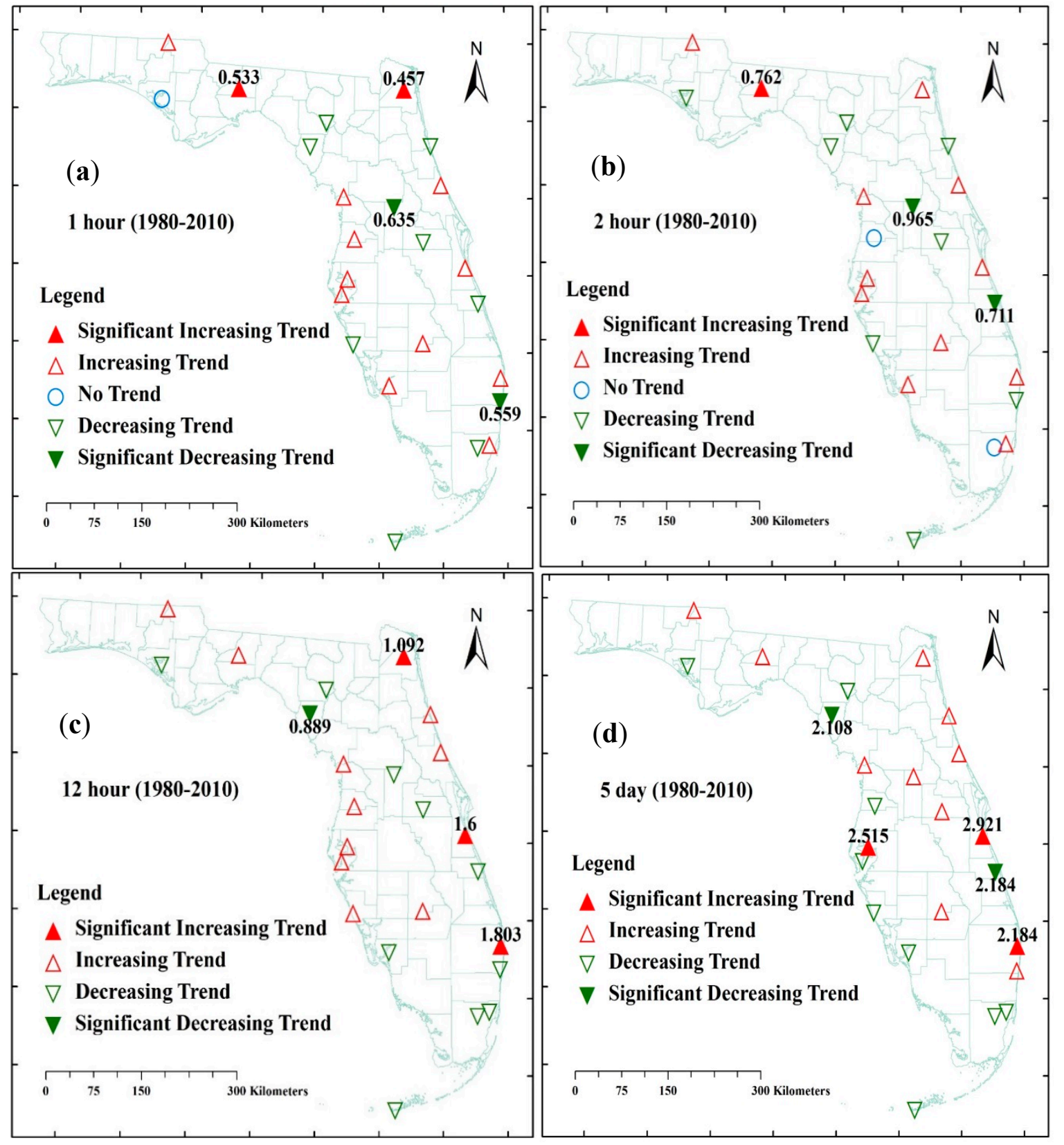

Figure 4. Spatial pattern of the trend results for the annual maximum rainfalls of (a) $1 \mathrm{~h}$, (b) $2 \mathrm{~h}$, (c) $12 \mathrm{~h}$, and (d) 5 day durations for the 1980-2010 analysis period. The slope value (mm/year) for locally significant trend is also indicated.

During the shortest period (1980-2010), the annual number of above-threshold events for 1 and $2 \mathrm{~h}$ rainfalls (Figure 6a,b) showed significant increasing trends in south Florida (Fort Myers), while demonstrating significant decreasing trends in Suwanee River Basin (Cross City) and northwest Florida (Panama City). Further, the number of $2 \mathrm{~h}$ extreme rainfall had significant decreasing trends in southwest Florida (St. Petersburg) and upper St. Johns Basin (Vero Beach). The number of $6 \mathrm{~h}$ extreme rainfall exhibited a prevalent and significant decreasing trends with the stations in Panama City, Cross City, West Palm Beach, Vero Beach, and Marineland (Figure 6c). In contrast, the annual number 
of 7 day extreme rainfall (Figure 6d) had significant increasing trends in southwest Florida (Tampa), south Florida (Boca Raton, West Palm Beach), and in upper St. John Basin (Melbourne). However, similar to 2 and $6 \mathrm{~h}$ rainfalls, the stations in Cross City and Vero Beach exhibited significant decreasing trends in the number of 7 day rainfall.
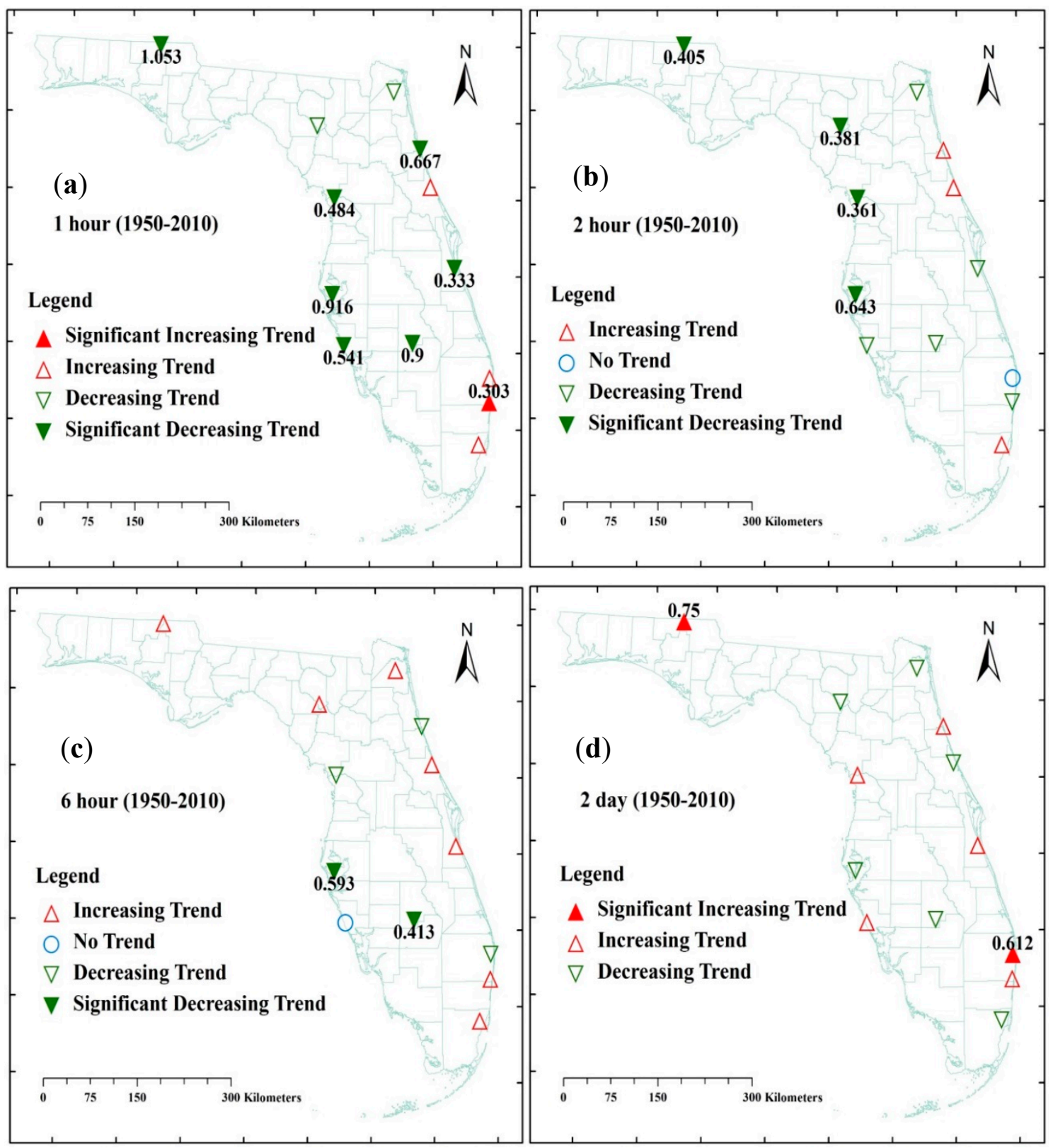

Figure 5. Spatial pattern of the trend results for the annual number of above-threshold events for (a) $1 \mathrm{~h}$, (b) $2 \mathrm{~h}$, (c) $6 \mathrm{~h}$, and (d) 2 day rainfalls during the 1950-2010 analysis period. The slope value (events/year) for locally significant trend is also indicated.

\section{Discussion}

Overall, statistically significant dominant increasing trends were evident in the magnitudes of short to medium duration rainfalls for the longest period (1950-2010) and in the magnitudes of medium to longer duration rainfalls for the shortest period (1980-2010) (Table 2). In contrast, mostly decreasing significant trends in the annual number of above-threshold events were found in short to medium duration rainfalls for all four periods of analysis. Although statistically significant increasing only trends in the annual number of 1-7 day (except for 2 day) extreme rainfalls were evident during 
1970-2010, more decreasing than increasing significant trends were noted in the number of 1-5 day rainfalls during 1980-2010. However, the number of 6-7 day extreme rainfalls had more increasing than decreasing trends during 1980-2010. Therefore, the trends in the frequencies of the 1-5 day extreme rainfalls were rather inconclusive. However, the magnitude of annual maximum rainfalls, as well as their number of above-threshold events, typically exhibited a higher rate of change per year during the more recent periods.

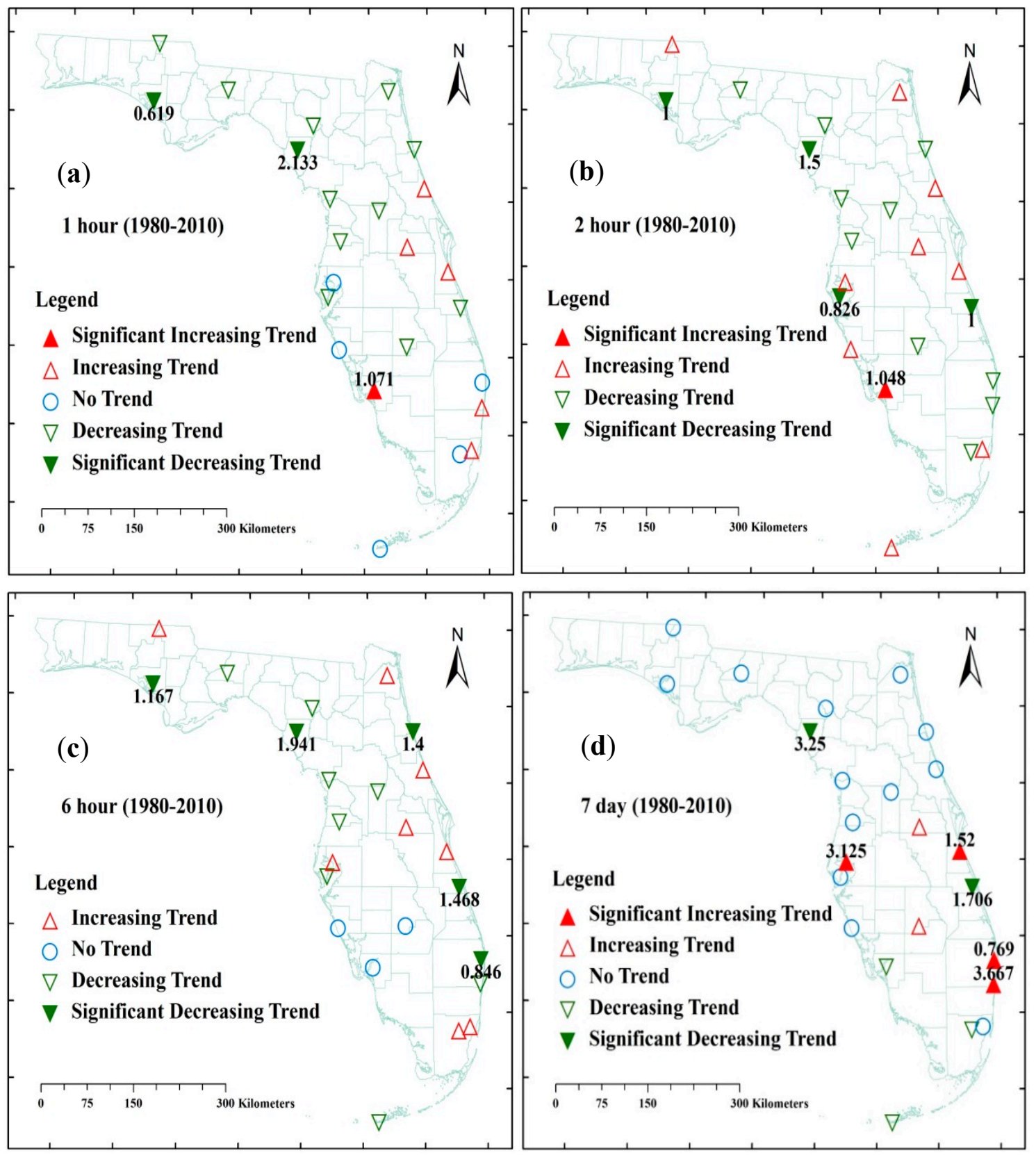

Figure 6. Spatial pattern of the trend results for the annual number of above-threshold events for (a) $1 \mathrm{~h}$, (b) $2 \mathrm{~h}$, (c) $6 \mathrm{~h}$, and (d) 7 day rainfalls during the 1980-2010 analysis period. The slope value (events/year) for locally significant trend is also indicated.

Our findings complemented previous studies for Florida and elsewhere in the world, indicating the transferability of our results especially to tropical and subtropical regions. For example, Luong et al. [17] found more intense (increasing magnitudes), but less frequent (decreasing number of events) extreme rainfalls over Jeddah, Saudi Arabia during 1979-2018. Nkrumah et al. [58] reported a similar pattern 
in the trends of magnitude and frequency of extreme rainfalls along the coast of southern West Africa during 1990-2010. Bisht et al. [59] found dominant increasing trends in 1-5 day extreme rainfall magnitudes in India; they suggested urbanization and climatic factors (e.g., temperature) as possible drivers of these rainfall trends. Notaro et al. [60] reported increasing trends in the amounts of hourly extreme rainfalls during 1950-2008 in southern Italy. Syafrina et al. [61] found overall increasing trends in hourly extreme rainfalls in peninsular Malaysia during 1975-2010, suggesting contributions from the potentially changing convective storm systems. Guerreiro et al. [62] suggested the rising temperature as a key cause for the increasing magnitudes of hourly rainfall extremes over Australia during 1990-2013. Herath et al. [63] reported increasing linkages of short duration extreme rainfalls with temperature across south-western, southern, and south-eastern coasts of Australia during 1908-2010. Peterson et al. [29] attributed the increasing trends in extreme rainfalls over North America during 1970-2000 to global warming. Feng et al. [64] attributed the increasing trends in springtime extreme rainfall magnitudes to more frequent and intense convective storms in the central U.S. Niyogi et al. [65] reported a slight decrease in extreme rainfall amounts and frequencies during 1958-2008 over the southeastern U.S. However, they also found an overall increasing trend in extreme rainfalls over urban areas across the eastern U.S. In contrast, van Oldenborgh et al. [66] and Wang et al. [67] attributed the intensification of extreme rainfall events along the Gulf of Mexico in recent decades to the global warming phenomena.

We posit that the dominant increasing trends in the magnitudes of short to medium duration extreme rainfalls during 1950-2013 over Florida were likely caused by the increasing surface temperatures [9,33], which is often used as a proxy for anthropogenic forcings such as increasing greenhouse gas emissions and land use/cover changes. In contrast, the dominant decreasing trends in the annual frequencies of short to medium duration rainfalls over Florida for our four periods of analysis could be attributed to a combination of anthropogenic forcings and natural variability represented by ENSO, PDO, North Atlantic Oscillation (NAO), and AMO [31]. The anthropogenic effects (specifically rising temperature) might have led to more intense convective storms of hourly durations, whereas their frequencies could have been impacted by both the anthropogenic forcings and naturally-occurring large-scale inter-annual to multi-decadal ocean-atmospheric oscillations. However, Teegavarapu et al. [35] detected significantly increasing trends in the magnitude of extreme rainfalls with duration longer than 1 day during the AMO's warm phase of 1995-2010 in Florida. They associated the increasing trends in the longer duration extreme rainfalls with the increased landfalls of tropical hurricanes and storms in the region. Knight and Davis [68] also indicated increasing contributions of tropical cyclones to the extreme precipitations during 1972-2007 in the southeast Atlantic coast. The findings were consistent with the dominant increasing trends in the magnitudes of 1-7 day rainfalls over Florida during 1980-2010 in our study.

Irizarry-Ortiz et al. [9] found decreasing only significant trends in the magnitude of 2 day extreme rainfall for 2 out 32 stations located across Florida during 1950-2008. They also reported significant increasing and decreasing trends in the magnitude of 3 day extreme rainfalls at 1 and 2 stations, respectively. Further, they found significant increasing trend in the magnitude of 7 day extreme rainfall. Despite these trends representing a small percentage of total stations, their results might be considered somewhat in contrast with our findings of no significant trends in the magnitude of 2-7 day extreme rainfalls during 1950-2010. The discrepancy might have occurred due to the different sets of gauging stations in the two studies. However, Irizarry-Ortiz et al. [9]'s results on the trends in the number of extreme events for 2-7 day extreme rainfalls were in agreements with our findings (Table 3).

Quality of dataset is an important criterion for trend analysis. The hourly precipitation dataset for this analysis was subjected to rigorous quality control procedures by the National Climatic Data Center [46]. Further, much precaution was taken in this study to select stations with least inhomogeneities (typically caused by movement of stations). Other sources of uncertainty include outlying and missing data, which can impact the trend results, specifically using parametric methods such as the ordinary least squares regression. However, we have used Mann-Kendall non-parametric 
method, which is known to be relatively robust to outliers [33,36-38]. Further, stations having more than four missing years in any period of analysis were excluded in our study to avoid any potential bias of excessive missing data in the trend results. The spatiotemporal correlation structures of time-series data can also impact the outcomes of a trend analysis [51]. We utilized a trend-free pre-whitening approach $[51,53,54]$ to correct the extreme rainfall time-series for autocorrelations. We also employed a bootstrap resampling approach to account for cross-correlations across sites and evaluate the global significance of trends. The global significance indicated whether the number of rainfall stations with locally (at-site level) significant trends had exceeded the number expected to occur by chance.

\section{Conclusions}

We computed the long-term trends in the extreme rainfall regimes of Florida by employing the non-parametric Mann-Kendall test and Theil-Sen slope estimator for four analysis periods: 1950-2010, 1960-2010, 1970-2010, and 1980-2010. The local and global significance of trends were evaluated at the $10 \%$ level (i.e., $p$-value $\leq 0.10)$. During the longest period (1950-2010), significant increasing trends were found in annual maximum rainfall magnitudes of 1-12 h and 1 day durations, whereas 2-7 day extreme rainfalls had no significant trends. However, only the increasing trends in the $2-12 \mathrm{~h}$ extreme rainfalls were globally significant (i.e., exceeded the trends that could occur by chance). The trend patterns changed in the more recent, shorter study periods. During the shortest period (1980-2010), magnitudes of 6-12 h and 1-7 day extreme rainfalls had dominant increasing trends, whereas 1-3 h rainfalls exhibited mixed increasing and decreasing trends. However, none of the detected trends during 1980-2010 were globally significant.

The annual number of above-threshold events (frequency) exhibited dominant decreasing trends for $1-6 \mathrm{~h}$ rainfalls in all four time periods. Trends in the annual number of $12 \mathrm{~h}$ to 7 day extreme rainfalls were not found significant during 1950-2010 (except for 2 day rainfall) and 1960-2010 (except for 7 day rainfall). However, the number of 1 day and 3-7 day extreme rainfalls had locally significant increasing trends during 1970-2000. In contrast, during 1980-2000, dominant decreasing and increasing trends were found, respectively, in the number of 1-5 day and 6-7 day extreme rainfalls. However, only the decreasing trends in the number of 1-3 h, 1-6 h, and 3-6 h extreme rainfalls were globally significant during 1950-2010, 1960-2010, and 1980-2010, respectively.

In summary, our study suggested less frequent (decreasing number of events), but more intense (increasing magnitudes) extreme rainfall regimes of short to moderate durations over Florida (globally significant) during 1950-2010. In contrast, locally significant dominant increasing trends were evident in the magnitudes of medium to longer duration rainfalls during 1980-2010. Further, we found higher rates of change per year in both magnitudes and frequencies of these extreme rainfall regimes during the more recent study periods. The changing extreme rainfall regimes would pose formidable challenges for water resources management in Florida. The low elevations, flat topography, and growing urban centers make Florida particularly vulnerable to flooding under a changing climate and rising sea level. Heavy rainfalls can lead to pluvial (due to rainfall accumulation in the watershed) and fluvial (due to overflowing river) floods, which have enormous impacts on human lives and properties. The detected trends in extreme rainfall would guide local and regional water management authorities to plan for necessary mitigation and adaptation strategies. The presented spatial distributions of significant trends can help set regional priorities for flood mitigation and management. The research findings can, therefore, aid in updating stormwater management infrastructure and practices in complex urban-natural environments of Florida and in tropical/subtropical regions around the world.

Author Contributions: O.I.A.-A. conceptualized the research idea and designed the methods. T.M. and O.I.A.-A. conducted analyses and summarized the results. Both authors contributed to the writing. O.I.A.-A. administered the projects and supervised T.M. All authors have read and agreed to the published version of the manuscript.

Funding: The research was funded by the Florida Public Hurricane Loss Model Enhancements project and by a U.S. National Science Foundation (NSF) Critical Resilient Interdependent Infrastructure Systems and Processes 
(CRISP 2.0) award to O.I.A.-A. (NSF CMMI Award \#1832680). The conclusions are those of the authors, and do not necessarily reflect the views of NSF or the State of Florida.

Acknowledgments: We are grateful to the two anonymous reviewers for their insightful comments. We are also thankful to the Editor for his high quality suggestions and guidance.

Conflicts of Interest: The authors declare no conflict of interest.

\section{References}

1. Parry, M.L.; Canziani, O.; Palutikof, J.; Van der Linden, P.; Hanson, C. Climate Change 2007-Impacts, Adaptation and Vulnerability: Working Group II Contribution to the Fourth Assessment Report of the IPCC; Cambridge University Press: Cambridge, UK, 2007; Volume 4.

2. Pachauri, R.K.; Allen, M.R.; Barros, V.R.; Broome, J.; Cramer, W.; Christ, R.; Church, J.A.; Clarke, L.; Dahe, Q.; Dasgupta, P. Climate Change 2014: Synthesis Report. Contribution of Working Groups I, II and III to the Fifth Assessment Report of the Intergovernmental Panel on Climate Change; IPCC: Geneva, Switzerland, 2014.

3. Meehl, G.A.; Stocker, T.F.; Collins, W.D.; Friedlingstein, P.; Gaye, A.T.; Gregory, J.M.; Kitoh, A.; Knutti, R.; Murphy, J.M.; Noda, A. Global Climate Projections. Climate Change 2007: The Physical Science Basis. Contribution of Working Group I to the Fourth Assessment Report of the Intergovernmental Panel on Climate Change; Cambridge University Press: Cambridge, UK, 2007.

4. Bates, B.; Kundzewicz, Z.; Wu, S. Climate Change and Water; Intergovernmental Panel on Climate Change Secretariat: Geneva, Switzerland, 2008.

5. Mailhot, A.; Beauregard, I.; Talbot, G.; Caya, D.; Biner, S. Future changes in intense precipitation over Canada assessed from multi-model NARCCAP ensemble simulations. Int. J. Climatol. 2012, 32, 1151-1163. [CrossRef]

6. Willems, P.; Arnbjerg-Nielsen, K.; Olsson, J.; Nguyen, V.T.V. Climate change impact assessment on urban rainfall extremes and urban drainage: Methods and shortcomings. Atmos. Res. 2012,103, 106-118. [CrossRef]

7. Mailhot, A.; Kingumbi, A.; Talbot, G.; Poulin, A. Future changes in intensity and seasonal pattern of occurrence of daily and multi-day annual maximum precipitation over Canada. J. Hydrol. 2010, 388, 173-185. [CrossRef]

8. Obeysekera, J.; Park, J.; Irizarry-Ortiz, M.; Trimble, P.; Barnes, J.; VanArman, J.; Said, W.; Gadzinski, E. Past and Projected Trends in Climate and Sea Level for South Florida; South Florida Water Management District: Miami, FL, USA, 2011.

9. Irizarry-Ortiz, M.M.; Obeysekera, J.; Park, J.; Trimble, P.; Barnes, J.; Park-Said, W.; Gadzinski, E. Historical trends in Florida temperature and precipitation. Hydrol. Process. 2013, 27, 2225-2246. [CrossRef]

10. Lettenmaier, D.P.; Wood, E.F.; Wallis, J.R. Hydro-climatological trends in the continental United States, 1948-1988. J. Clim. 1994, 7, 586-607. [CrossRef]

11. Small, D.; Islam, S.; Vogel, R.M. Trends in precipitation and streamflow in the eastern U.S.: Paradox or perception? Geophys. Res. Lett. 2006, 33, L03403. [CrossRef]

12. Wang, H.; Schubert, S.; Suarez, M.; Chen, J.; Hoerling, M.; Kumar, A.; Pegion, P. Attribution of the Seasonality and Regionality in Climate Trends over the United States during 1950-2000. J. Clim. 2009, 22, 2571-2590. [CrossRef]

13. Karl, T.R.; Knight, R.W. Secular trends of precipitation amount, frequency, and intensity in the United States. Bull. Am. Meteorol. Soc. 1998, 79, 231-242. [CrossRef]

14. Pryor, S.C.; Howe, J.A.; Kunkel, K.E. How spatially coherent and statistically robust are temporal changes in extreme precipitation in the contiguous USA? Int. J. Climatol. 2009, 29, 31-45. [CrossRef]

15. Sayemuzzaman, M.; Jha, M.K. Seasonal and annual precipitation time series trend analysis in North Carolina, United States. Atmos. Res. 2014, 137, 183-194. [CrossRef]

16. Longueville, F.D.; Hountondji, Y.-C.; Kindo, I.; Gemenne, F.; Ozer, P. Long-term analysis of rainfall and temperature data in Burkina Faso (1950-2013). Int. J. Climatol. 2016, 36, 4393-4405. [CrossRef]

17. Luong, T.M.; Dasari, H.P.; Hoteit, I. Extreme precipitation events are becoming less frequent but more intense over Jeddah, Saudi Arabia. Are shifting weather regimes the cause? Atmos. Sci. Lett. 2020, 21. [CrossRef]

18. Frich, P.; Alexander, L.V.; Della-Marta, P.M.; Gleason, B.; Haylock, M.; Tank, A.K.; Peterson, T. Observed coherent changes in climatic extremes during the second half of the twentieth century. Clim. Res. 2002, 19, 193-212. [CrossRef] 
19. Costa, A.C.; Soares, A. Trends in extreme precipitation indices derived from a daily rainfall database for the South of Portugal. Int. J. Climatol. 2009, 29, 1956-1975. [CrossRef]

20. Burn, D.H.; Mansour, R.; Zhang, K.; Whitfield, P.H. Trends and Variability in Extreme Rainfall Events in British Columbia. Can. Water Resour. J. 2011, 36, 67-82. [CrossRef]

21. Burn, D.H.; Taleghani, A. Estimates of changes in design rainfall values for Canada. Hydrol. Process. 2013, 27, 1590-1599. [CrossRef]

22. Yilmaz, A.G.; Hossain, I.; Perera, B.J.C. Effect of climate change and variability on extreme rainfall intensity-frequency-duration relationships: A case study of Melbourne. Hydrol. Earth Syst. Sci. 2014, 18, 4065-4076. [CrossRef]

23. Malik, N.; Bookhagen, B.; Mucha, P.J. Spatiotemporal patterns and trends of Indian monsoonal rainfall extremes. Geophys. Res. Lett. 2016, 43, 1710-1717. [CrossRef]

24. Papalexiou, S.M.; Montanari, A. Global and Regional Increase of Precipitation Extremes under Global Warming. Water Resour. Res. 2019, 2018WR024067. [CrossRef]

25. Kunkel, K.E.; Easterling, D.R.; Redmond, K.; Hubbard, K. Temporal variations of extreme precipitation events in the United States: 1895-2000. Geophys. Res. Lett. 2003, 30. [CrossRef]

26. Kunkel, K.E.; Karl, T.R.; Easterling, D.R. A Monte Carlo assessment of uncertainties in heavy precipitation frequency variations. J. Hydrometeorol. 2007, 8, 1152-1160. [CrossRef]

27. Mishra, A.K.; Singh, V.P. Changes in extreme precipitation in Texas. J. Geophys. Res. 2010, 115, D14106. [CrossRef]

28. Keuser, A.P. Precipitation patterns and trends in the metropolitan area of Milwaukee, Wisconsin. Int. J. Geospatial Environ. Res. 2014, 1, 6.

29. Peterson, T.C.; Zhang, X.; Brunet-India, M.; Vázquez-Aguirre, J.L. Changes in North American extremes derived from daily weather data. J. Geophys. Res. 2008, 113, D07113. [CrossRef]

30. Powell, E.J.; Keim, B.D. Trends in Daily Temperature and Precipitation Extremes for the Southeastern United States: 1948-2012. J. Clim. 2015, 28, 1592-1612. [CrossRef]

31. Armal, S.; Devineni, N.; Khanbilvardi, R. Trends in Extreme Rainfall Frequency in the Contiguous United States: Attribution to Climate Change and Climate Variability Modes. J. Clim. 2018, 31, 369-385. [CrossRef]

32. Nadarajah, S. Extremes of daily rainfall in West Central Florida. Clim. Chang. 2005, 69, 325-342. [CrossRef]

33. Martinez, C.J.; Maleski, J.J.; Miller, M.F. Trends in precipitation and temperature in Florida, USA. J. Hydrol. 2012, 452-453, 259-281. [CrossRef]

34. Kendon, E.J.; Blenkinsop, S.; Fowler, H.J. When Will We Detect Changes in Short-Duration Precipitation Extremes? J. Clim. 2018, 31, 2945-2964. [CrossRef]

35. Teegavarapu, R.S.V.; Goly, A.; Obeysekera, J. Influences of Atlantic multidecadal oscillation phases on spatial and temporal variability of regional precipitation extremes. J. Hydrol. 2013, 495, 74-93. [CrossRef]

36. Mann, H.B. Nonparametric tests against trend. Econ. J. Econ. Soc. 1945, 13, 245-259. [CrossRef]

37. Kendall, M.G. A new measure of rank correlation. Biometrika 1938, 30, 81-93. [CrossRef]

38. Kendall, M.G. Rank Auto Correlation Methods, 4th ed.; Griffin: Oxford, UK, 1976.

39. Theil, H. A Rank-Invariant Method of Linear and Polynomial Regression Analysis. In Henri Theil's Contributions to Economics and Econometrics; Raj, B., Koerts, J., Eds.; Advanced Studies in Theoretical and Applied Econometrics; Springer: Dordrecht, The Netherlands, 1992; Volume 23, pp. 345-381. ISBN 978-94-010-5124-8.

40. Sen, P.K. Estimates of the Regression Coefficient Based on Kendall's Tau. J. Am. Stat. Assoc. 1968, 63, 1379-1389. [CrossRef]

41. NOAA National Centers for Environmental Information. Available online: https://www.ncdc.noaa.gov/cag/ (accessed on 14 September 2020).

42. McPherson, B.F.; Halley, R. The South Florida Environment: A Region Under Stress; Circular 1134; USGS: Reston, VA, USA, 1996.

43. Obeysekera, J.; Trimble, P.J.; Neidrauer, C.; Pathak, C.; Vanarman, J.; Strowd, T.; Hall, C. Consideration of Long-Term Climatic Variability in Regional Modeling for SFWMD Planning and Operations; SFWMD Report: West Palm Beach, FL, USA, 2006; p. 50.

44. Obeysekera, J.; Irizarry, M.; Park, J.; Barnes, J.; Dessalegne, T. Climate change and its implications for water resources management in south Florida. Stoch. Environ. Res. Risk Assess. 2011, 25, 495-516. [CrossRef]

45. Garbrecht, J.D.; Piechota, T.C. (Eds.) Climate Variations, Climate Change, and Water Resources Engineering; American Society of Civil Engineers: Reston, VA, USA, 2005; ISBN 978-0-7844-0824-7. 
46. NCDC National Climatic Data Center. Available online: https://www.ncdc.noaa.gov/ (accessed on 29 July 2020).

47. Kunkel, K.E.; Andsager, K.; Easterling, D.R. Long-term trends in extreme precipitation events over the conterminous United States and Canada. J. Clim. 1999, 12, 2515-2527. [CrossRef]

48. Burn, D.H. Climatic influences on streamflow timing in the headwaters of the Mackenzie River Basin. J. Hydrol. 2008, 352, 225-238. [CrossRef]

49. Douglas, E.M.; Fairbank, C.A. Is precipitation in northern New England becoming more extreme? Statistical analysis of extreme rainfall in Massachusetts, New Hampshire, and Maine and updated estimates of the 100-year storm. J. Hydrol. Eng. 2011, 16, 203-217. [CrossRef]

50. Burn, D.H.; Hag Elnur, M.A. Detection of hydrologic trends and variability. J. Hydrol. 2002, 255, 107-122. [CrossRef]

51. Burn, D.H.; Cunderlik, J.M.; Pietroniro, A. Hydrological trends and variability in the Liard River basin. Hydrol. Sci. J. 2004, 49, 53-67. [CrossRef]

52. Novotny, E.V.; Stefan, H.G. Stream flow in Minnesota: Indicator of climate change. J. Hydrol. 2007, 334, 319-333. [CrossRef]

53. Yue, S.; Pilon, P.; Cavadias, G. Power of the Mann-Kendall and Spearman's rho tests for detecting monotonic trends in hydrological series. J. Hydrol. 2002, 259, 254-271. [CrossRef]

54. Yue, S.; Pilon, P.; Phinney, B.; Cavadias, G. The influence of autocorrelation on the ability to detect trend in hydrological series. Hydrol. Process. 2002, 16, 1807-1829. [CrossRef]

55. Hirsch, R.M.; Slack, J.R.; Smith, R.A. Techniques of trend analysis for monthly water quality data. Water Resour. Res. 1982, 18, 107-121. [CrossRef]

56. Zhang, X.; Vincent, L.A.; Hogg, W.D.; Niitsoo, A. Temperature and precipitation trends in Canada during the 20th century. Atmosphere-Ocean 2000, 38, 395-429. [CrossRef]

57. Tabari, H.; Somee, B.S.; Zadeh, M.R. Testing for long-term trends in climatic variables in Iran. Atmos. Res. 2011, 100, 132-140. [CrossRef]

58. Nkrumah, F.; Vischel, T.; Panthou, G.; Klutse, N.A.B.; Adukpo, D.C.; Diedhiou, A. Recent Trends in the Daily Rainfall Regime in Southern West Africa. Atmosphere 2019, 10, 741. [CrossRef]

59. Bisht, D.S.; Chatterjee, C.; Raghuwanshi, N.S.; Sridhar, V. Spatio-temporal trends of rainfall across Indian river basins. Theor. Appl. Climatol. 2018, 132, 419-436. [CrossRef]

60. Notaro, V.; Liuzzo, L.; Freni, G.; La Loggia, G. Uncertainty Analysis in the Evaluation of Extreme Rainfall Trends and Its Implications on Urban Drainage System Design. Water 2015, 7, 6931-6945. [CrossRef]

61. Syafrina, A.H.; Zalina, M.D.; Juneng, L. Historical trend of hourly extreme rainfall in Peninsular Malaysia. Theor. Appl. Climatol. 2015, 120, 259-285. [CrossRef]

62. Guerreiro, S.B.; Fowler, H.J.; Barbero, R.; Westra, S.; Lenderink, G.; Blenkinsop, S.; Lewis, E.; Li, X.-F. Detection of continental-scale intensification of hourly rainfall extremes. Nat. Clim. Chang. 2018, 8, 803-807. [CrossRef]

63. Herath, S.M.; Sarukkalige, R.; Nguyen, V.T.V. Evaluation of empirical relationships between extreme rainfall and daily maximum temperature in Australia. J. Hydrol. 2018, 556, 1171-1181. [CrossRef]

64. Feng, Z.; Leung, L.R.; Hagos, S.; Houze, R.A.; Burleyson, C.D.; Balaguru, K. More frequent intense and long-lived storms dominate the springtime trend in central US rainfall. Nat. Commun. 2016, 7, 13429. [CrossRef] [PubMed]

65. Niyogi, D.; Lei, M.; Kishtawal, C.; Schmid, P.; Shepherd, M. Urbanization Impacts on the Summer Heavy Rainfall Climatology over the Eastern United States. Earth Interact. 2017, 21, 1-17. [CrossRef]

66. Van Oldenborgh, G.J.; van der Wiel, K.; Sebastian, A.; Singh, R.; Arrighi, J.; Otto, F.; Haustein, K.; Li, S.; Vecchi, G.; Cullen, H. Attribution of extreme rainfall from Hurricane Harvey, August 2017. Environ. Res. Lett. 2017, 12, 124009. [CrossRef]

67. Wang, S.-Y.S.; Zhao, L.; Yoon, J.-H.; Klotzbach, P.; Gillies, R.R. Quantitative attribution of climate effects on Hurricane Harvey's extreme rainfall in Texas. Environ. Res. Lett. 2018, 13, 054014. [CrossRef]

68. Knight, D.B.; Davis, R.E. Contribution of tropical cyclones to extreme rainfall events in the southeastern United States. J. Geophys. Res. 2009, 114, D23102. [CrossRef]

(C) 2020 by the authors. Licensee MDPI, Basel, Switzerland. This article is an open access article distributed under the terms and conditions of the Creative Commons Attribution (CC BY) license (http://creativecommons.org/licenses/by/4.0/). 